\title{
A short review: Comparisons of high-throughput phenotyping methods for detecting
}

\section{drought tolerance}

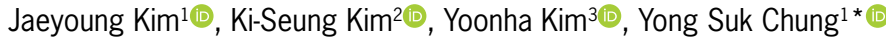

\author{
1 Jeju National University - Dept. of Plant Resources and \\ Environment, Jejudaehak-ro 102, 63243, Jeju-si, Jeju-do - \\ South Korea. \\ FarmHannong Ltd., Daejeon 34115 - South Korea. \\ ${ }^{3}$ Kyungpook National University - Major in Plant Bioscience, \\ Daegu 41566, South Korea. \\ *Corresponding author <yschung@jejunu.ac.kr>
}

Edited by: Leonardo Medici

Received November 11, 2019

Accepted February 10, 2020

\begin{abstract}
Drought is a major threat worldwide for crop production, especially due to the rapid climate changes. Current drought solutions involve improving irrigation system, rainwater harvesting, damming, cloud seeding, and changes of cultivation methods. Despite effective, each solution has economic, environmental, and temporal drawbacks. Among all solutions, the most effective, inexpensive and manageable method is the use of drought-tolerant cultivars via plant breeding. However, conventional plant breeding is a time-consuming and laborious task, especially for phenotypic data acquisition of target traits of numerous progenies. Highthroughput phenotyping (HTP) is a recently developed method and has potential to overcome the mentioned issues. HTP offers massive, accurate, rapid, and automatic data acquisition in the breeding procedure and can be a breakthrough for developing drought resistant/tolerant cultivars. This study introduces various methods of HTP to detect drought stress, which can accelerate the breeding processes of drought-tolerant cultivars to provide helpful guidelines for breeders and researchers to choose appropriate methods.
\end{abstract}

Keywords: sensors, remote sensing platforms, image analysis, drought solution, plant breeding

\section{Introduction}

Expanding global population demands crop production to double by 2050, which poses a significant challenge (Araus and Cairns, 2014). However, recent variation of drought frequency and locations are increasing tremendously due to the global warming and climate change, causing severe yield loss to crops (Spinoni et al., 2014), which could compromise food security worldwide.

Numerous studies have investigated drought effects on crops and tolerances by identifying plant physiology against drought. Therefore, characterization of plant physiology identified that the development of drought-tolerant cultivars is the most effective method to deal with the current situation by providing farmers a relatively inexpensive and manageable crop procedure (Cattivelli et al., 2008). However, to date, only few drought-tolerant cultivars have been developed. Moreover, conventional breeding takes many years, despite modern breeding processes, such as markerassisted selection (Collard and MacKill, 2008; Tester and Langridge, 2010). To enable shorter breeding cycles, great rates of genetic gain with the sufficient number of samples and a reliable dataset are required. This has led to the advent of new field, high throughput phenotyping (HTP) (Rutkoski et al., 2016). HTP is based on various types of sensors and computing technology in order to accelerate the process of phenotypic data acquisition using accurate, fast, non-invasive, automated, and reliable manners. Therefore, it is important to review various HTP methods to evaluate drought stress in crop plants to allow researchers to identify drought-tolerant phenotypes, compare them and use them in their purposes.
In order to monitor plant performance and identify traits under drought condition, defining phenotypes of drought stresses is crucial. Screening, analyzing, comparing drought-effective phenotypes, physiological performance of plants, and their production can be helpful to determine the most appropriate traits for evaluating drought tolerance based on functional phenotyping (York, 2018). For instance, dehydration under drought conditions results in critical damage to plants by changing leaf and canopy temperature, transpiration rate, and biomass distribution influence growth rates and yields (Khodarahmpour, 2011; Passioura, 1983). As rates of changes of these traits have considerable correlations (Kimball and Bernacchi, 2006), the most efficient phenotypes and screening methods could be selected for drought studies. Thus, various ways to screen drought stress level with different types of sensors to screen each of those components are necessary. This article reviews HTP methods and platforms.

\section{High throughput phenotyping methods for drought stress in plants}

\section{Red, green, and blue (RGB) image}

Optical sensor is a device that applies radiometry as a source of detection and image acquisition (Holland et al., 2012). Numerous ranges of electromagnetic wavelengths are used on image processing, such as visible band (VIS), infrared (IR), and ultraviolet (UV) (Araus et al., 2018). Classification of electromagnetic wavelengths and features of applying sensors are shown in Figure 1 and Table 1. Multispectral sensors generally comprise several bands including Red, Green, Blue (RGB) channels and Near Infrared (NIR) channels 


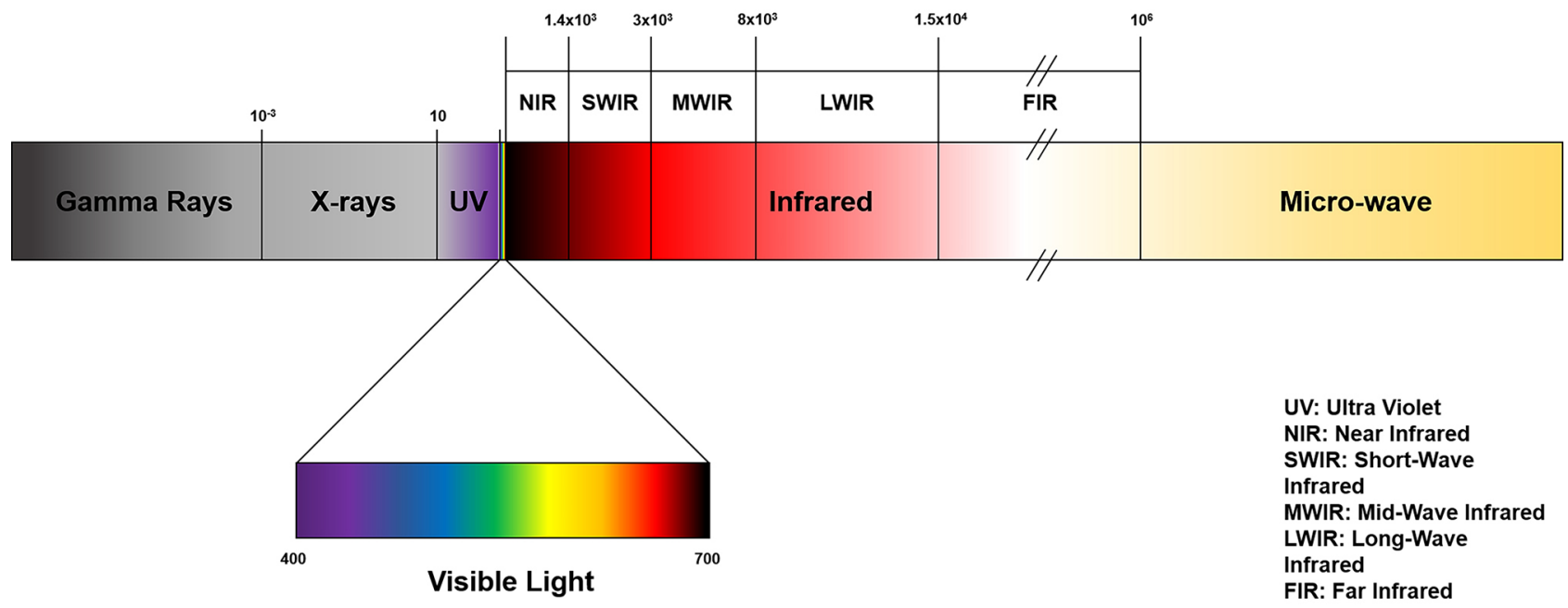

Figure 1 - Electromagnetic spectrum scheme (nm).

Table 1 - Sensors for high throughput imaging and obtainable traits.

\begin{tabular}{|c|c|c|c|c|}
\hline Sensors & Wavelength & Features & Traits & Reference \\
\hline $\begin{array}{l}\text { RGB (Red, green, blue) } \\
\text { sensor }\end{array}$ & $400 \sim 700 \mathrm{~nm}$ & $\begin{array}{l}\text { Sensing visible wavelengths. Most easily } \\
\text { accessible sensor. }\end{array}$ & $\begin{array}{l}\text { Vegetation indices, plant height, } \\
\text { plant structure, growth rates, and } \\
\text { morphological traits. }\end{array}$ & $\begin{array}{l}\text { Kim et al. (2018); Crimmins and } \\
\text { Crimmins (2008); Deery et al. (2014); } \\
\text { Liu et al. (2017) }\end{array}$ \\
\hline $\begin{array}{l}\text { NIR (Near infrared) } \\
\text { sensor }\end{array}$ & $700 \sim 1400$ nm & $\begin{array}{l}\text { Sensing highest reflectance of plant green } \\
\text { area in } 700 \sim 1300 \mathrm{~nm} \text {, while beyond } \\
1300 \mathrm{~nm} \text { shows more absorbance by } \\
\text { water than the visible spectrum. }\end{array}$ & $\begin{array}{l}\text { Chlorophyll conductance, water } \\
\text { status, and vegetation indices. }\end{array}$ & $\begin{array}{l}\text { Bei et al. (2011); Bendig et al. } \\
\text { (2015); Thiel et al. (2010); Yang et } \\
\text { al. (2017) }\end{array}$ \\
\hline Hyperspectral sensor & - & $\begin{array}{l}\text { Sensing thousands of bands per pixel. } \\
\text { More detailed images can be obtained } \\
\text { than the multispectral imaging if the } \\
\text { requirements are set. }\end{array}$ & $\begin{array}{l}\text { Vegetation and water indices, soil } \\
\text { cover status, photosynthesis rates, } \\
\text { and levels of phytochemicals. }\end{array}$ & $\begin{array}{l}\text { Hamada et al. (2007); Stagakis et } \\
\text { al. (2010); Zhao et al. (2013); El- } \\
\text { 'Hendawy et al. (2019a); El-Hendawy } \\
\text { et al. (2019b) }\end{array}$ \\
\hline Thermal sensor & $700 \sim 10^{6} \mathrm{~nm}$ & $\begin{array}{l}\text { Sensing emitted radiation of object that } \\
\text { increases with the object temperature } \\
\text { above absolute zero. Suitable to image } \\
\text { temperature changes. }\end{array}$ & $\begin{array}{l}\text { Canopy temperature, transpiration } \\
\text { rates, and water stress responses. }\end{array}$ & $\begin{array}{l}\text { Baluja et al. (2012); Berni et al. } \\
\text { (2009); Gago et al. (2015); Leinonen } \\
\text { et al. (2006) }\end{array}$ \\
\hline Fluorescence sensor & $180 \sim 800 \mathrm{~nm}$ & $\begin{array}{l}\text { Sensing fluorescence emitted by short } \\
\text { wave light absorption of susceptible } \\
\text { molecule. }\end{array}$ & $\begin{array}{l}\text { Chlorophyll conductance, } \\
\text { photosynthetic rates, and pigment } \\
\text { composition. }\end{array}$ & $\mathrm{Ch}$ \\
\hline $\begin{array}{l}\text { LiDAR (Light Detection } \\
\text { and Ranging) }\end{array}$ & $250 \sim 2,000 \mathrm{~nm}$ & $\begin{array}{l}\text { Surface scan of target objects and } \\
\text { distance measurement by analyzing the } \\
\text { reflected light. }\end{array}$ & $\begin{array}{l}\text { Canopy and leaves, vegetation } \\
\text { cover, plant height, and nitrogen } \\
\text { status. }\end{array}$ & $\begin{array}{l}\text { Lin (2015); Eitel et al. (2014); Madec } \\
\text { et al. (2017); Omasa et al. (2006); } \\
\text { Zhang and Grift (2012); }\end{array}$ \\
\hline $\begin{array}{l}\text { Others } \\
\text {-MRI }\end{array}$ & - & $\begin{array}{l}\text { Feasible to screen underground structures } \\
\text { of plant by } 3 \mathrm{D} \text { imaging and transport } \\
\text { processes in natural porous media. }\end{array}$ & $\begin{array}{l}\text { Water contents, stem structures, } \\
\text { root structures, transport } \\
\text { processes }\end{array}$ & $\begin{array}{l}\text { Capitani et al. (2009); Gosa et al. } \\
\text { (2019); Pohlmeier et al. (2008); Van } \\
\text { As and Van Dusschoten (1997) }\end{array}$ \\
\hline $\begin{array}{l}\text { Others } \\
\text {-Gravimetric senor }\end{array}$ & - & $\begin{array}{l}\text { Capable of measuring plant physiological } \\
\text { changes by non-imaging process. } \\
\text { Requires other sensors for screening. }\end{array}$ & $\begin{array}{l}\text { Weight, water use efficiency, } \\
\text { water status, transpiration rates, } \\
\text { biomass. }\end{array}$ & $\begin{array}{l}\text { Halperin et al. (2017); Iyer-Pascuzzi } \\
\text { et al. (2010); Negin and Moshelion } \\
\text { (2017). }\end{array}$ \\
\hline
\end{tabular}

(Kelcey and Lucieer, 2012). Relatively insensitive accessibility of spectral imagery allowed various forms of its usage. RGB band sensor is the most affordable and accessible instrument because it takes images of most morphological features of plants, such as whole image or partial image of plant, plant structure, shoot biomass, leaf density, leaf area, height, and color. Due to its rapid measurement and affordable access, RGB has various applications. For example, wheat plant density was estimated with light platform fixed on an RGB camera (Liu et al., 2017), time series of plant phenology was monitored with an automated time-lapse 
photography (Crimmins and Crimmins, 2008), and leaf segmentation of sorghum was estimated based on the correlation between target traits and RGB values taken by camera on unmanned aerial vehicles (UAVs) (Kim et al., 2018). RGB images can also be applied to acquire sophisticated information on responses to water stress based on its shape, compactness, solidity, and other visible parameters (Deery et al., 2014).

\section{Infrared imaging}

Between $700 \mathrm{~nm}$ and $1300 \mathrm{~nm}$ near infrared (NIR) wavelengths, plant green area shows the highest rates of reflectance (Broge and Mortensen, 2002). NIR beyond $1300 \mathrm{~nm}$ is also reflected by plant tissues but with a relatively low rate. These processes cause the scattering of wavelengths within the leaf mesophyll, which lately are absorbed by water (Knipling, 1970). Such characteristics verify compatibility on meaningful parameters against drought stresses. Thiel et al. (2010) showed plant moisture measurement using NIR sensor attached to an automated conveyor platform and Bei et al. (2011) measured grapevine water potentials using a custom-made spectrophotometer and a handheld spectrometer to have significant correlation with the results of pressure chamber in fields and glasshouses by model-based estimations. Additionally, spectral reflectance indices (SRIs) based on NIR and RGB channel showed significant correlation on vegetation status. Bendig et al. (2015) and Yang et al. (2017) estimated the normalized difference vegetation index (NDVI) in order to monitor biomass in projected area with combination of RGB and NIR imagery on Unmanned Aerial Vehicles (UAVs). These sensors can be adapted to not only UAVs, but also to other platforms, such as ground vehicles and chambers to produce images of wide range and continuous images at each platform (Chapman et al., 2014; Deery et al., 2014; Gago et al., 2015).

\section{Hyperspectral imaging}

Hyperspectral sensors consist of hundreds and thousands of bands per one pixel compared to the other multispectral sensors (Thenkabail et al., 2002). Due to its narrow and numerous bands, which include ranges of VIS, NIR, fluorescence, thermal sensors, and so on, band selection is relatively complicated for imaging. Nevertheless, it can differentiate various responses to stress due to its viability to acquire images in high resolution and narrow spatial range. Thereby, hyperspectral imagery is often used for indoor imaging and high-altitude aerial platforms, due to its high level of details. Soil coverage status, photosynthesis rates, and levels of phytochemicals, such as nitrogen, cellulose, lignin, and pigments can be obtained due to its narrow ranges of spectral reflectance and water indices (Hamada et al., 2007; Stagakis et al., 2010; Zhao et al., 2013). Additionally, El-Hendawy et al. (2019b) showed the relationship between chlorophyll fluorescence parameters, grain yield, and SRIs of hyperspectral sensors in wheat grown under salinity. As sensitiveness of SRIs against plant stress reactions proved its reliability, assessable SRIs might be used in drought screening. Moreover, El-Hendawy et al. (2019a) compared dry weights, water contents, aboveground biomass, grain yield, and performance of SRIs in the VIS and NIR under two irrigation regimes for more precise analyses of SRIs by hyperspectral sensors. However, lighting issues in close range and inconstant imaging by environmental changes could be problematic for HTP (Mishra et al., 2017). Nonetheless, hyperspectral imaging is an effective tool for studies on drought in crops due to its efficient capability of acquiring physiological and phytochemical parameters, such as photosynthesis rates, soil coverage status, nitrogen status, water indices, and other various SRIs for detecting drought stress (Behmann et al., 2014).

\section{Thermal imaging}

Thermography, also known as infrared thermography, produces images using emitted radiation of object that increases as the object temperature is above absolute zero (Shekhawat, 2016). Thermal sensor can detect temperature changes caused by the occurrence of transpiration, due to the stomatal closure, using visualized image data (Peñuelas et al., 1992). Thereby, temperature-related traits, such as water content, transpiration rate, and stomatal conductance could be measured through thermal imaging by model-based estimations (Prashar et al., 2013; Tattaris et al., 2016). For example, stomatal conductance in grapevine (Vitis vinifera) was estimated with a handheld thermometer camera (Leinonen et al., 2006) and water stress in olives was evaluated through correlation between soil and tree water status and thermal imagery (Ben-Gal et al., 2009). HTP methods with thermal imagery are often applied with other sensors to obtain comprehensive data. For instance, thermal and multispectral sensors on UAVs for vegetation monitoring (Berni et al., 2009) were used to assess water status in vineyard (Baluja et al., 2012; Gago et al., 2015). Thermal images have significant correlation with water stress indicators and are thus the most useful sensors to phenotype drought-related traits. However, environmental factors, such as solar radiation, air temperature, wind speed, and background temperature can easily influence field measurements, requiring technical expertise to overcome this limitation (Sugiura et al., 2007).

\section{Fluorescence imaging}

Fluorescence is luminescence of longer wavelength photons of fluorescence lifetime after photon absorption by a certain susceptible atom or molecule (Lichtman and Conchello, 2005). These longer wavelengths and lower energy photons can be measured by fluorescence lifetime through the sensor in picoseconds or nanoseconds (Berezin and Achilefu, 2010). Thus, plant fluorescence can be obtained through responses of fluorescence by irradiating chloroplasts with blue or 
actinic light. As fluorescence and chlorophyll contents are strong indicators of drought tolerance to determine the metabolic status of plants, fluorescence imaging can be effective to identify drought related traits, such as photosynthetic rate changes and pigment proportion changes (Li et al., 2006; Ögren and Öquist, 1985; Zlatev and Yordanov, 2004). However, fluorescence imaging has limitations, such as impropriety for early water stress detection, inadequacy on broad range imagery, inconsistent lighting, environmental disruptions under field conditions for remote sensing, and requirements of high electric power (Jansen et al., 2009; Shakoor et al., 2017). Nonetheless, efficiency of fluorescence imaging is proven under drought conditions by the combination with other sensors or automated facilities to screen photosynthetic rates (Chaerle et al., 2006).

\section{Light Detection and Ranging (LiDAR)}

LiDAR is a new remoted sensing technology that measures distance of target objects by analyzing reflected light (Lefsky et al., 2002). It acquires various parameters of canopy and leaves, such as vegetation cover, height, canopy structure, leaf area index, and nitrogen status (Eitel et al., 2014; Lin, 2015; Madec et al., 2017; Omasa et al., 2006; Zhang and Grift, 2012). Furthermore, LiDAR measuring via $3 \mathrm{D}$ structuring can be done in a short time. It is generally applied in aerial platforms, ground vehicles, and ground fixed \& stationary platforms. UAVs show the highest potential and efficiency than the other platforms for 3D LiDAR mapping. Although LiDAR has limited application for studies on drought stress, some applications could be possible. Phenotypes that result from slow growth and wilting, due to drought stress, are based on 3D images, such as biomass and leaf area index. In summary, aerial platforms with LiDAR are effective for measuring canopy areas, while rough images might be unsuitable for accurate data for drought tolerance. To overcome this, ground based platforms are suggested with current image resolution of LiDAR.

\section{Other HTP sensors}

In addition to the sensors mentioned above, there are various other sensors available. HTP methods applying magnetic resonance microscopy and gravimetric sensors were studied (Gosa et al., 2019; IyerPascuzzi et al., 2010). Magnetic resonance microscopy, also known as magnetic resonance imaging (MRI), is a powerful 3D-imaging tool of structures, as it transports processes in natural porous media (Van As and Van Dusschoten, 1997). Non-invasive imaging of MRI allows characterization of responses of the entire plant area against drought. Pohlmeier et al. (2008) imaged both soil water contents and root architectures through magnetic resonance microscopy and indicated that greater water content changes occurred where the highest root densities were found. Capitani et al. (2009) showed relationships between nuclear magnetic resonance
(NMR) signal and relative water content on plant leaves exposed to dehydration or to osmotic stresses, indicating that the NMR signal has correlation with plant responses against drought (e.g. plant water status and transpiration rates).

Weighing lysimeter based on gravimetric sensor is also a useful tool for studies on drought effects. However, because plant physiology differs in terms of species and varieties, this sensor cannot be used alone for the HTP process. Halperin et al. (2017) installed soil and atmosphere sensors that can effectively estimate physiology of the target plant. Thereby, numerous phenotypes, including weight, water use efficiency, water status, transpiration rates, biomass, and more, are capable of screening and comparable through this functional physiological phenotyping system. Consequently, as this system determine appropriate traits in need, known to play critical roles in responses to environmental conditions and highly related to other plant physiological responses against drought stress, it can be a powerful HTP tool (Negin and Moshelion, 2017).

\section{Platforms for sensors to evaluate drought tolerance}

As previously mentioned, various sensors can provide parameters for HTP. They are powerful imaging instruments that allow accurate and massive phenotyping data at a glance. However, appropriate platforms are needed, such as aircrafts, vehicles, ground fixed, and automated facilities to place sensors in order to obtain visualized parameters of plant response under drought conditions. The features and usages of platforms are compared in Table 2.

Canopy traits, such as leaf area, transpiration rates, canopy temperature, phytochemicals, and photosynthetic rates are highly related to drought effects. Among various platforms, aerial detection is the most effective and efficient way in terms of phenotyping speed. Its rapid and accurate remote sensing allows imaging massive amounts of plant in a wide area within very short time. Visible traits of the canopy area, including plant height, can be easily measured by aerial imaging with RGB sensors (Bendig et al., 2014; Jin et al., 2017). Chlorophyll contents can be estimated by NIR and Red range by aerial imaging (Bendig et al., 2015; Yang et al., 2017). Thermal sensor mounted on aerial vehicles is capable of detecting aerial water status (Baluja et al., 2012; Berni et al., 2009; Gago et al., 2015). In addition, aerial platform with high payload can apply hyperspectral sensor for phytochemical and photosynthetic traits. However, application of thermal and fluorescence sensors might be more appropriate for ground vehicles, ground fixed \& stationary platforms, and indoor facilities for higher resolution images due to the issues mentioned previously (Busemeyer et al., 2013; Deery et al., 2014; Shafiekhani et al., 2017; Tisné et al., 2013). 
Table 2 - Platforms for High Throughput Phenotyping.

\begin{tabular}{|c|c|c|c|c|}
\hline Platforms & Categories & Features & Limits & References \\
\hline \multirow{3}{*}{ Aerial } & Satellites & \multirow{3}{*}{$\begin{array}{l}\text { Sensing broad area rapidly. } \\
\text { Payload limits. } \\
\text { Screening process is possible regardless } \\
\text { of plant height. } \\
\text { Only orthoimages can be obtained. }\end{array}$} & $\begin{array}{l}\text { Relatively low resolution images } \\
\text { than platforms on lower altitude. }\end{array}$ & $\begin{array}{l}\text { Hamada et al. (2007); Stagakis et } \\
\text { al. (2010) }\end{array}$ \\
\hline & \multirow[b]{2}{*}{ Aircraft } & & Manual control requires expertise. & Chapman et al. (2014) \\
\hline & & & $\begin{array}{l}\text { Easily influenced by environmental } \\
\text { factors. } \\
\text { Relatively low payloads. }\end{array}$ & $\begin{array}{l}\text { Baluja et al. (2012); Bendig et al. } \\
\text { (2014); Bendig et al. (2015); Berni et } \\
\text { al. (2009); Gago et al. (2015); Jin et } \\
\text { al. (2017); Yang et al. (2017) }\end{array}$ \\
\hline \multirow{4}{*}{ Ground } & Tractors \& Buggies & \multirow{2}{*}{$\begin{array}{l}\text { Manual or remote control. } \\
\text { High resolution images. } \\
\text { Sensor payload is independent. }\end{array}$} & \multirow{2}{*}{$\begin{array}{l}\text { Inappropriate to screen very tall } \\
\text { crops. }\end{array}$} & $\begin{array}{l}\text { Deery et al. (2014); Salas Fernandez } \\
\text { et al. (2017) }\end{array}$ \\
\hline & Bicycles & & & Liu et al. (2017) \\
\hline & $\begin{array}{l}\text { Ground-Fixed \& } \\
\text { Stationary }\end{array}$ & $\begin{array}{l}\text { Suitable to time-lapsed images. } \\
\text { More sensors are mountable than the } \\
\text { aerial platforms. }\end{array}$ & $\begin{array}{l}\text { Requires endurance against } \\
\text { outdoor conditions. }\end{array}$ & $\begin{array}{l}\text { Busemeyer et al. (2013); Shafiekhani } \\
\text { et al. (2017) }\end{array}$ \\
\hline & Indoor Facilities & $\begin{array}{l}\text { Environmental factors can be controlled. } \\
\text { Uncontrollable disturbances are inhibited. } \\
\text { Almost all sensors can be applied. } \\
\text { Capable of root phenotyping. }\end{array}$ & Personnel limitations. & $\begin{array}{l}\text { Clark et al. (2013); lyer-Pascuzzi et } \\
\text { al. (2010); Hartmann et al. (2011); } \\
\text { Marié et al. (2014); Taras et al. } \\
\text { (2012); Tisné et al. (2013); Wasaya } \\
\text { et al. (2018) }\end{array}$ \\
\hline
\end{tabular}

Despite the benefits for HTP, the detectable area of aerial platforms is limited to the top canopy area. Therefore, drought-related phenotypes below the canopy area, such as stem structure, biomass, and branching need to be remotely sensed by ground vehicles (Salas Fernandez et al., 2017), ground fixed \& stationary (Busemeyer et al., 2013; Shafiekhani et al., 2017), and indoor (Hartmann et al., 2011) platforms. Ground vehicles are relatively less expensive than other two kinds of ground-based platforms, while the images they acquire need to undergo analyses, similar to images from aerial platforms (Deery et al., 2014). Ground vehicles are also advantageous for their capacity of loading heavier sensors than aerial platform. However, phenotyping speed is much slower than that of images acquired from aerial platform. Indoor platforms have benefits of controlling the target environment due to the inhibition of other uncontrollable disturbances. By restricting interference of extrinsic factors, almost all sensors are available on this platform. Proper posture rectified for each imaging sensor can make the measurement more accurate and rapid with easier operation. Ground fixed \& stationary platforms have the advantage of producing time-lapsed image easily due to their fixed imaging angle and constant imaging time; however, they have to be highly durable under the outdoor conditions. Indoor facilities are also capable of phenotyping roots formed under drought conditions, providing important hints to drought tolerance (Wasaya et al., 2018). However, personnel limitations, high cost, and environmental settings are drawbacks. Cylinder growth systems, hydroponic growth systems, aeroponic growth systems, X-rays, nuclear magnetic resonance microscopy, magnetic resonance imaging, and laser scanning are currently available for indoor phenotyping (Clark et al., 2013; Marié et al., 2014; Taras et al., 2012).

\section{Final Remarks}

Droughts are some of the main factors of food crisis worldwide, which can be overcome by the development of drought-tolerant cultivars via plant breeding. Since droughts occur more often in severe forms, the breeding cycle should be significantly shortened. To achieve this, massive and accurate phenotypic data are crucial. Given that responses to drought stress are related to various morphological and physiological traits, numerous methods could be applied using sensors, such as multispectral, hyperspectral, thermal, fluorescence sensors, and laser sensors on various platforms.

In this study, recently developed HTP methods and platforms were reviewed for drought screening. For instance, researchers searching for a cost-effective HTP drought screening method, RGB and NIR imaging with aerial platform or ground vehicle might be a proper selection. In order to screen in-field conditions, aerial platforms are more efficient in large area screening while having low payloads for sensors. Unlike aerial platforms, ground vehicles are more efficient in narrow areas and capable of carrying multiple sensors. However, for more accurate and consistent screening, ground fixed and stationary platforms might be a suitable selection. Despite its high cost, users willing to use in strictly controlled environmental conditions and various sensors, indoor platform might be a proper choice. In addition, remotely controlled ground vehicles and indoor phenotyping systems can provide below canopy area images with various sensors by user's choices and financial constraints. Our objective was to help researchers who need to conduct HTP for drought responses. We sincerely hope that this article could help those who consider studying drought response or breeding drought-tolerant cultivars. 


\section{Acknowledgements}

This research was supported by a grant from the Next-Generation BioGreen 21 Program (Project No. PJ01451203), Rural Development Administration, Republic Korea. Also, we are grateful to Sustainable Agricultural Research Institute (SARI) in Jeju National University for providing the experimental facilities.

\section{Authors' Contributions}

Conceptualization: Chung, Y.S. Writing and editing: Kim, J.Y.; Kim, K.S.; Kim, Y.H.

\section{References}

Araus, J.L.; Cairns, J.E. 2014. Field high-throughput phenotyping: the new crop breeding frontier. Trends in Plant Science 19: 52-61.

Araus, J.L.; Kefauver, S.C.; Zaman-Allah, M.; Olsen, M.S.; Cairns, J.E. 2018. Translating high-throughput phenotyping into genetic gain. Trends in Plant Science 23: 451-466.

Baluja, J.; Diago, M.P.; Balda, P.; Zorer, R.; Meggio, F.; Morales, F.; Tardaguila, J. 2012. Assessment of vineyard water status variability by thermal and multispectral imagery using an Unmanned Aerial Vehicle (UAV). Irrigation Science 30: 511522 .

Behmann, J.; Steinrücken, J.; Plümer, L. 2014. Detection of early plant stress responses in hyperspectral images. ISPRS Journal of Photogrammetry and Remote Sensing 93: 98-111.

Bei, R.; Cozzolino, D.; Sullivan, W.; Cynkar, W.; Fuentes, S.; Dambergs, R.; Pech, J.; Tyerman, S. 2011. Non-destructive measurement of grapevine water potential using near infrared spectroscopy. Australian Journal of Grape and Wine Research 17: 62-71.

Bendig, J.; Bolten, A.; Bennertz, S.; Broscheit, J.; Eichfuss, S.; Bareth, G. 2014. Estimating biomass of barley using Crop Surface Models (CSMs) derived from UAV-based RGB imaging. Remote Sensing 6: 10395-10412.

Bendig, J.; Yu, K.; Aasen, H.; Bolten, A.; Bennertz, S.; Broscheit, J.; Gnyp, M.L.; Bareth, G. 2015. Combining UAV-based plant height from crop surface models, visible, and near infrared vegetation indices for biomass monitoring in barley. International Journal of Applied Earth Observation and Geoinformation 39: 79-87.

Ben-Gal, A.; Agam, N.; Alchanatis, V.; Cohen, Y.; Yermiyahu, U.; Zipori, I.; Presnov, E.; Sprintsin, M.; Dag, A. 2009. Evaluating water stress in irrigated olives: correlation of soil water status, tree water status, and thermal imagery. Irrigation Science 27: 367-376.

Berezin, M.Y.; Achilefu, S. 2010. Fluorescence lifetime measurements and biological imaging. Chemical Reviews 110: 2641-2684.

Berni, J.A.J.; Zarco-Tejada, P.J.; Suarez, L.; Fereres, E. 2009. Thermal and narrowband multispectral remote sensing for vegetation monitoring from an unmanned aerial vehicle. IEEE Transactions on Geoscience and Remote Sensing 47: 722-738.
Broge, N.H.; Mortensen, J.V. 2002. Deriving green crop area index and canopy chlorophyll density of winter wheat from spectral reflectance data. Remote Sensing of Environment 81: 45-57.

Busemeyer, L.; Mentrup, D.; Möller, K.; Wunder, E.; Alheit, K.; Hahn, V.; Maurer, H.P.; Reif, J.C.; Würschum, T.; Müller, J.; Rahe, F.; Ruckelshausen, A. 2013. Breedvision: a multi-sensor platform for non-destructive field-based phenotyping in plant breeding. Sensors 13: 2830-2847.

Capitani, D.; Brilli, F.; Mannina, L.; Proietti, N.; Loreto, F. 2009. In situ investigation of leaf water status by portable unilateral nuclear magnetic resonance. Plant Physiology 149: 1638-1647.

Cattivelli, L.; Rizza, F.; Badeck, F.W.; Mazzucotelli, E.; Mastrangelo, A.M.; Francia, E.; Marè, C.; Tondelli, A.; Stanca, A.M. 2008. Drought tolerance improvement in crop plants: a integrated view from breeding to genomics. Field Crops Research 105: 1-14.

Chaerle, L.; Leinonen, I.; Jones, H.G.; Van Der Straeten, D. 2006. Monitoring and screening plant populations with combined thermal and chlorophyll fluorescence imaging. Journal of Experimental Botany 58: 773-784.

Chapman, S.; Merz, T.; Chan, A.; Jackway, P.; Hrabar, S.; Dreccer, M.; Holland, E.; Zheng, B.; Jun Ling, T.; Berni, J. 2014. PhenoCopter: a low-altitude, autonomous remote-sensing robotic helicopter for high-throughput field-based phenotyping. Agronomy 4: 279-301.

Clark, R.T.; Famoso, A.N.; Zhao, K.; Shaff, J.E.; Craft, E.J.; Bustamante, C.D.; McCouch, S.R.; Aneshansley, D.J.; Kochian, L.V. 2013. High-throughput two-dimensional root system phenotyping platform facilitates genetic analysis of root growth and development. Plant, Cell \& Environment 36: 454466.

Collard, B.C.; MacKill, D.J. 2008. Marker-assisted selection: an approach for precision plant breeding in the twenty-first century. Philosophical Transactions of the Royal Society B: Biological Sciences 363: 557-572.

Crimmins, M.A.; Crimmins, T.M. 2008. Monitoring plant phenology using digital repeat photography. Environmental Management 41: 949-958.

Deery, D.; Jimenez-Berni, J.; Jones, H.; Sirault, X.; Furbank, R. 2014. Proximal remote sensing buggies and potential applications for field-based phenotyping. Agronomy 4: 349-379.

Eitel, J.U.H.; Magney, T.S.; Vierling, L.A.; Brown, T.T.; Huggins, D.R. 2014. LiDAR based biomass and crop nitrogen estimates for rapid, non-destructive assessment of wheat nitrogen status. Field Crops Research 159: 21-32.

El-Hendawy, S.E.S.; Alotaibi, M.; Al-Suhaibani, N.; Al-Gaadi, K.; Hassan, W.M.; Dewir, Y.H.; Emam, M.A.E.; Elsayed, S.E.M.; Schmidhalter, U. 2019a. Comparative performance of spectral reflectance indices and multivariate modeling for assessing agronomic parameters in advanced spring wheat lines under two contrasting irrigation regimes. Frontiers in Plant Science 10: 1537-1556.

El-Hendawy, S.E.S.; Al-Suhaibani, N.; Elsayed, S.E.M.; Alotaibi, M.; Hassan, W.M.; Schmidhalter, U. 2019b. Performance of optimized hyperspectral reflectance indices and partial least squares regression for estimating the chlorophyll fluorescence and grain yield of wheat grown in simulated saline field conditions. Plant Physiology and Biochemistry 144: 300-311. 
Gago, J.; Douthe, C.; Coopman, R.E.; Gallego, P.P.; Ribas-Carbo, M.; Flexas, J.; Escalona, J.; Medrano, H. 2015. UAVs challenge to assess water stress for sustainable agriculture. Agricultural Water Management 153: 9-19.

Gosa, S.C.; Lupo, Y.; Moshelion, M. 2019. Quantitative and comparative analysis of whole-plant performance for functional physiological traits phenotyping: new tools to support pre-breeding and plant stress physiology studies. Plant Science 282: 49-59.

Halperin, O.; Gebremedhin, A.; Wallach, R.; Moshelion, M. 2017. High-throughput physiological phenotyping and screening system for the characterization of plant-environment interactions. The Plant Journal 89: 839-850.

Hamada, Y.; Stow, D.A.; Coulter. L.L.; Jafolla, J.C.; Hendricks, L.W. 2007. Detecting tamarisk species (Tamarix spp.) in riparian habitats of southern California using high spatial resolution hyperspectral imagery. Remote Sensing of Environment 109: 237-248.

Hartmann, A.; Czauderna, T.; Hoffmann, R.; Stein, N.; Schreiber, F. 2011. HTPheno: an image analysis pipeline for highthroughput plant phenotyping. BMC Bioinformatics 12: 148156.

Holland, K.H.; Lamb, D.W.; Schepers, J.S. 2012. Radiometry of proximal Active Optical Sensors (AOS) for agricultural sensing. IEEE Journal of Selected Topics in Applied Earth Observations and Remote Sensing 5: 1793-1802.

Iyer-Pascuzzi, A.S.; Symonova, O.; Mileyko, Y.; Hao, Y.; Belcher, H.; Harer, J.; Weitz, J.S.; Benfey, P.N. 2010. Imaging and analysis platform for automatic phenotyping and trait ranking of plant root systems. Plant Physiology 152: 1148-1157.

Jansen, M.; Gilmer, F.; Biskup, B.; Nagel, K.; Rascher, U.; Fischbach, A.; Briem, S.; Dreissen, G.; Tittmann, S.; Braun, S.; De Jaeger, I.; Metzlaff, M.; Schurr, U.; Scharr, H.; Walter, A. 2009. Simultaneous phenotyping of leaf growth and chlorophyll fluorescence via GROWSCREEN FLUORO allows detection of stress tolerance in Arabidopsis thaliana and other rosette plants. Functional Plant Biology 36: 902914.

Jin, X.; Liu, S.; Baret, F.; Hemerlé, M.; Comar, A. 2017. Estimates of plant density of wheat crops at emergence from very low altitude UAV imagery. Remote Sensing of Environment 198: 105-114.

Kelcey, J.; Lucieer, A. 2012. Sensor correction of a 6-band multispectral imaging sensor for UAV remote sensing. Remote Sensing 4: 1462-1493.

Khodarahmpour, Z. 2011. Effect of drought stress induced by polyethylene glycol (PEG) on germination indices in corn (Zea mays L.) hybrids. African Journal of Biotechnology 10: 1822218227.

Kim, D.W.; Yun, H.S.; Jeong, S.J.; Kwon, Y.S.; Kim, S.G.; Lee, W.S.; Kim, H.J. 2018. Modeling and testing of growth status for Chinese cabbage and white radish with UAV-based RGB imagery. Remote Sensing, 10: 563-587

Kimball, B.A.; Bernacchi, C.J. 2006. Evapotranspiration, canopy temperature, and plant water relations. p. 311-324. In: Nösberger, J.; Long, S.P.; Norby, R.J.; Stitt, M.; Hendrey, G.R.; Blum, H., eds. Managed ecosystems and $\mathrm{CO}_{2}$. Springer, Berlin, Germany.
Knipling, E.B. 1970. Physical and physiological basis for the reflectance of visible and near-infrared radiation from vegetation. Remote Sensing of Environment 1: 155-159.

Lefsky, M.A.; Cohen, W.B.; Parker, G.G.; Harding, D.J. 2002. Lidar remote sensing for ecosystem studies: lidar, an emerging remote sensing technology that directly measures the threedimensional distribution of plant canopies, can accurately estimate vegetation structural attributes and should be of particular interest to forest, landscape, and global ecologists. BioScience 52: 19-30.

Leinonen, I.; Grant, O.M.; Tagliavia, C.P.P.; Chaves, M.M.; Jones, H.G. 2006. Estimating stomatal conductance with thermal imagery. Plant, Cell and Environment 29: 1508-1518.

Li, R.; Guo, P.; Michael, B.; Stefania, G.; Salvatore, C. 2006. Evaluation of chlorophyll content and fluorescence parameters as indicators of drought tolerance in barley. Agricultural Sciences in China 5: 751-757.

Lichtman, J.W.; Conchello, J.A. 2005. Fluorescence microscopy. Nature Methods 2: 910-919.

Lin, Y. 2015. Lidar: an important tool for next-generation phenotyping technology of high potential for plant phenomics? Computers and Electronics in Agriculture 119: 61-73.

Liu, S.; Baret, F.; Andrieu, B.; Burger, P.; Hemmerlé, M. 2017. Estimation of wheat plant density at early stages using high resolution imagery. Frontiers in Plant Science 8: 1-10.

Madec, S.; Baret, F.; de Solan, B.; Thomas, S.; Dutartre, D.; Jezequel, S.; Hemmerlé, M.; Colombeau, G.; Comar, A. 2017. High-throughput phenotyping of plant height: comparing unmanned aerial vehicles and ground lidar estimates. Frontiers in Plant Science 8: 2002-2015.

Marié, C.L.; Kirchgessner, N.; Marschall, D.; Walter, A.; Hund, A. 2014. Rhizoslides: paper-based growth system for nondestructive, high throughput phenotyping of root development by means of image analysis. Plant Methods 10: 13-28.

Mishra, P.; Mohd Shahrimie, M.A.; Ana, H.L.; Santosh, L.; Belén, D.; Paul, S. 2017. Close range hyperspectral imaging of plants: a review. Biosystems Engineering 164: 49-67.

Negin, B.; Moshelion, M. 2017. The advantages of functional phenotyping in pre-field screening for drought-tolerant crops. Functional Plant Biology 44: 107-118.

Omasa, K.; Hosoi, F.; Konishi, A. 2006. 3D lidar imaging for detecting and understanding plant responses and canopy structure. Journal of Experimental Botany 58: 881-898.

Ögren, E.; Öquist, G. 1985. Effects of drought on photosynthesis, chlorophyll fluorescence and photoinhibition susceptibility in intact willow leaves. Planta 166: 380-388.

Passioura, J.B. 1983. Roots and drought resistance. Developments in Agricultural and Managed Forest Ecology 12: 265-280.

Peñuelas, J.; Savé, R.; Marfà, O.; Serrano, L. 1992. Remotely measured canopy temperature of greenhouse strawberries as indicator of water status and yield under mild and very mild water stress conditions. Agricultural and Forest Meteorology 58: 63-77.

Pohlmeier, A.; Oros-Peusquens, A.; Javaux, M.; Menzel, M.I.; Vanderborght, J.; Kaffanke, J.; Romanzetti, J.; Lindenmair, H.; Shah, N.J. 2008. Changes in soil water content resulting from Ricinus root uptake monitored by magnetic resonance imaging. Vadose Zone Journal 7: 1010-1017. 
Prashar, A.; Yildiz, J.; McNicol, J.W.; Bryan, G.J.; Jones, H.G. 2013. Infra-red thermography for high throughput field phenotyping in Solanum tuberosum. PLoS One 8: e65816.

Rutkoski, J.; Poland, J.; Mondal, S.; Autrique, E.; Pérez, L.G.; Crossa, J.; Reynolds, M.; Singh, R. 2016. Canopy temperature and vegetation indices from high-throughput phenotyping improve accuracy of pedigree and genomic selection for grain yield in wheat. G3: Genes|Genomes|Genetics 6: 2799-2808.

Salas Fernandez, M.G.; Bao, Y.; Tang, L.; Schnable, P.S. 2017. A high-throughput, field-based phenotyping technology for tall biomass crops. Plant Physiology 174: 2008-2022.

Shafiekhani, A.; Kadam, S.; Fritschi, F.; DeSouza, G.N. 2017. Vinobot and Vinoculer: two robotic platforms for highthroughput field phenotyping. Sensors 17: 214-236.

Shakoor, N.; Lee, S.; Mockler, T.C. 2017. High throughput phenotyping to accelerate crop breeding and monitoring of diseases in the field. Current Opinion in Plant Biology 38: 184192.

Shekhawat, R.S. 2016. Infrared thermography: a review. International Journal of Engineering Trends and Technology 35: 287-290.

Spinoni, J.; Naumann, G.; Carrao, H.; Barbosa, P.; Vogt, J. 2014. World drought frequency, duration, and severity for 19512010. International Journal of Climatology 34: 2792-2804.

Stagakis, S.; Markos, N.; Sykioti, O.; Kyparissis, A. 2010. Monitoring canopy biophysical and biochemical parameters in ecosystem scale using satellite hyperspectral imagery: an application on a Phlomis fruticosa Mediterranean ecosystem using multiangular CHRIS/PROBA observations. Remote Sensing of Environment 114: 977-994.

Sugiura, R.; Noguchi, N.; Ishii, K. 2007. Correction of lowaltitude thermal images applied to estimating soil water status. Biosystems Engineering 96: 301-313.

Tattaris, M.; Reynolds, M.P.; Chapman, S.C. 2016. A direct comparison of remote sensing approaches for high-throughput phenotyping in plant breeding. Frontiers in Plant Science 7: 1131-1139.
Tisné, S.; Serrand, Y.; Bach, L.; Gilbault, E.; Ben Ameur, R.; Balasse, H.; Voisin, R.; Bouchez, D.; Durand-Tardif, M.; Guerche, P.; Chareyron, G.; Da-Rugna, J.; Camilleri, C.; Loudet, O. 2013. Phenoscope: an automated large-scale phenotyping platform offering high spatial homogeneity. The Plant Journal 74: 534-544.

Tester, M.; Langridge, P. 2010. Breeding technologies to increase crop production in a changing world. Science 327: 818-822.

Thenkabail, P.S.; Smith, R.B.; De Pauw, E. 2002. Evaluation of narrowband and broadband vegetation indices for determining optimal hyperspectral wavebands for agricultural crop characterization. Photogrammetric Engineering and Remote Sensing 68: 607-622.

Van As, H.; Van Dusschoten, D. 1997. NMR methods for imaging of transport processes in micro-porous systems. Geoderma 80: 389-403.

Wasaya, A.; Zhang, X.; Fang, Q.; Yan, Z. 2018. Root phenotyping for drought tolerance: a review. Agronomy 8: 241-259.

Yang, G.; Liu, J.; Zhao, C.; Li, Z.; Huang, Y.; Yu, H.; Xu, B.; Yang, X.; Zhu, D.; Zhang, X.; Zhang, R.; Feng, H.; Zhao, X.; Li, Z.; Li, H.; Yang, H. 2017. Unmanned aerial vehicle remote sensing for field-based crop phenotyping: current status and perspectives. Frontiers in Plant Science 8: 1111-1136.

York, L.M. 2018. Functional phenomics: an emerging field integrating high-throughput phenotyping, physiology, and bioinformatics. Journal of Experimental Botany 70: 379-386.

Zhang, L.; Grift, T.E. 2012. A lidar-based crop height measurement system for Miscanthus giganteus. Computers and Electronics in Agriculture 85: 70-76.

Zhao, K.; Valle, D.; Popescu, S.; Zhang, X.; Mallick, B. 2013. Hyperspectral remote sensing of plant biochemistry using Bayesian model averaging with variable and band selection. Remote Sensing of Environment 132: 102-119.

Zlatev, Z.S.; Yordanov, I.T. 2004. Effects of soil drought on photosynthesis and chlorophyll fluorescence in bean plant. Plant Physiology 30: 3-18. 